\title{
Investigation and analysis on the illumination of the university classroom
}

\author{
WANG Rong, HE Xiao-yang, LIU Shen, LIU Liang-chang, LIU Bao, WANG \\ Zhi-sheng, YANG Yi, YU Ling*
}

Research Institute of Photonics, Dalian Polytechnic University, Dalian 116034, China

Keywords: Lighting environment; university classroom; National Standard; Illumination parameters

\begin{abstract}
Appropriate classroom lighting environment in universities should be able to meet the needs of the students physical and mental, and it has the practical significance to improve the student' vision, physical and mental health and learning efficiency. The paper uses the subjective and objective research method to investigate and analyse the present illumination situation of the university classroom based on the national standard of the <Architectural Lighting Design Standards>: GB50034-2013. According to the research results, we put forward the improvement scheme of the automatic control mode of the four kinds of classroom illumination and add the blackboard lamps, and then use the DIALux software to simulate the improvement effect, and obtain the energy saving benefit analysis table, so we can provides the program and data support for the classroom lighting.
\end{abstract}

\section{The introduction}

According to the research center of China healthy development in Peking University, Adolescent myopia prevalence has been ranked the first in the world[1].The $<2010$ national physique monitoring result bulletin of Beijing> shows:the eyesight unqualified rate of junior high school students reaches $71 \%$, the high school students is $81 \%$,the college students is as high as $90 \%$, More important is that the level continues to grow [2]. Therefore, the influence of the classroom lighting conditions on the students' vision becomes increasingly visible.

The classroom is the main place for students to study in school, and the classroom lighting constitute the artificial light environment for students to study . Human visual activity is closely related with the activities of the whole organism and higher nervous system. When the lighting environment is not suitable for vision of people, the visual efficiency declined significantly. This will not only affect visual fatigue, myopia, central nervous system ,but also the body activity will be subdued.Once appear this kind of situation,The students will feel exhausted of body and mind and the attention is susceptible to interference.So,it will reduce the learning efficiency. Good classroom lighting design should be able to meet the needs of the students physical and mental and suitable for students for a long period to study and work. It not only has the appropriate illuminance value, but also the all the parameters should meet the requirements of lighting quality.This will provide better lighting environment[3]. Therefore, the suitable university classroom lighting environment to improve the students' vision, physical and mental health and learning efficiency has important practical significance [4].

\section{School building lighting design standard [5]}

In order to guarantee on the work needed for visual brightness and brightness contrast [6], the national ministry of construction term definition and standard of architectural lighting design indexes.

\section{Illumination.}

The value of the luminous flux per unit area, name as $: E=d \Phi / d A$. The amount of the symbol for the E, the unit for lux (lx), $1 \mathrm{~lx}=1 \mathrm{~lm} / \mathrm{m} 2$.

\section{Intensity of illumination evenness.}

On the surface of the minimum intensity of illumination and the ratio of the average illuminance, symbols for U0. 


\section{Chamber shape index.}

The geometry of the room Numbers. Its calculation formula is:

$$
\mathrm{RI}=2 \mathrm{~s} / \mathrm{h} * 1
$$

Room type, RI: shape index; S: room area; L: room level circumference; H: calculated height of lamps and lanterns.

\section{The lighting power density.}

Lighting installation power per unit area (including the light source, ballast or transformer), the unit of watts per square meter $(\mathrm{W} / \mathrm{m} 2)$.

$$
\text { The LDP }=\text { Eav/eta } \mathrm{s} * \mathrm{U} * \mathrm{~K}
$$

Type in the Eav: maintain the average illuminance; Eta s: the room light source (including ballast) average photosynthetic efficiency, $\mathrm{lm} / \mathrm{W}$. U: utilization coefficient; K: maintenance coefficient.

Tab.1 Standard for education building illumination

\begin{tabular}{cc}
\hline lighting target & numerical value \\
\hline The blackboard illumination & \\
(lx) & 500 \\
Desktop illumination evenness & 0.60 \\
The blackboard lighting & 0.70 \\
uniformity & 9.0 \\
lighting power density $(\mathrm{W} / \mathrm{m} 2)$ & 1.5 \\
room index & 80 \\
color rendering $(\mathrm{Ra})$ & Small diameter straight tube fluorescent \\
light source & $\leq 4000$ \\
color temperature $(\mathrm{K})$ & 3.00 \\
mounting height of luminaire & \\
$(\mathrm{m})$ &
\end{tabular}

\section{The classroom lighting measurement}

To understand and analyze the present situation of university classroom lighting based on college classroom lighting as the research object, from the present situation of lighting two aspects of objective measurements and subjective evaluation, investigation analysis about the present situation of classroom lighting [4], and on the basis of new standards, to make scientific and rational survey evaluation and Suggestions for improvement.

\section{Subjective survey.}

1) Respondents

For all the students in university, a random sample of 400 as the respondents, through the way of questionnaire to fill out the classroom lighting, complete the subjective satisfaction survey.

2) Survey content

The blackboard and surface clear, different types of classroom lighting overall satisfaction, satisfaction the blackboard lighting, lamps and lanterns installation direction and height rationality, satisfaction survey rationality automatic lighting control mode, etc.

3) Evaluation method

Through regression analysis [7] anomalies observed value analysis of survey data, and the direct comparison method analysis of respondents to the classroom lighting indicators of satisfaction.

4) Data processing and analysis

a) Students surveyed on the classroom lighting satisfaction

Through random surveys, to enter the classroom lighting satisfaction survey EXCEL spreadsheet, as shown in table 2. 
Tab.2 The satisfactory table of classroom illumination

\begin{tabular}{ccccc}
\hline & $\begin{array}{c}\text { Working surface } \\
\text { brightness }\end{array}$ & $\begin{array}{c}\text { Lamps and lanterns } \\
\text { installation direction }\end{array}$ & $\begin{array}{c}\text { mounting } \\
\text { height of } \\
\text { luminaire }\end{array}$ & $\begin{array}{c}\text { auto-control } \\
\text { mode }\end{array}$ \\
\hline I & 29.55 & 15.91 & 20.45 & 18.18 \\
II & 43.18 & 45.45 & 38.64 & 22.73 \\
III & 18.18 & 18.18 & 20.45 & 20.45 \\
IV & 9.09 & 15.91 & 11.36 & 31.82 \\
V & 0 & 4.54 & 9.10 & 6.82 \\
\hline
\end{tabular}

Note: I: satisfaction degree is high, II: III: higher satisfaction degree and satisfaction degree, IV: satisfaction degree is low, V: satisfaction is low. Numerical units: \%.

The data import minitab16 software, using regression analysis survey data authenticity and rationality, and regression model equation are obtained. The results of the analysis as shown in table 3.

Satisfaction value $=-2.02165+0.156879 \times$ Working surface brightness- $0.136964 \times$ Lamps and lanterns installation direction $+0.0394721 \times$ The installation height of lamps and lanterns + $0.0416817 \times$ Automatic control mode

Tab.3 Analysis of variance of regression equation

\begin{tabular}{ccccc}
\hline variance & $\begin{array}{c}\text { Degree of } \\
\text { freedom }\end{array}$ & Seq SS & Adj SS & Adj MS \\
\hline $\begin{array}{c}\text { regression model } \\
\text { Working surface } \\
\text { brightness }\end{array}$ & 4 & 10.00 & 10.00 & 2.50 \\
$\begin{array}{c}\text { Lamps and lanterns } \\
\text { installation direction } \\
\text { mounting height of }\end{array}$ & 1 & 7.55 & 1.27 & 1.27 \\
$\begin{array}{c}\text { luminaire } \\
\text { auto-control mode }\end{array}$ & 1 & 2.18 & 0.32 & 0.32 \\
\hline
\end{tabular}

Can be concluded from table 3, survey data values, there is no abnormal observations, namely real effective survey data, by the survey data concludes truly reflect the surveyed students' satisfaction about the present situation of classroom lighting.

Can be seen from table 2, the surveyed students satisfied with the teaching classroom lighting face brightness degree is high, the installation height of lamps and lanterns and the direction of the satisfaction, satisfaction with the minimum of automatic control mode. Need to declare, the school classroom existing automatic control mode for the keying infrared type lamps and lanterns, when meet the signal lamps and lanterns is normal work. Thus, the school students' consciousness of energy conservation and environmental protection is increasing, hope the classroom lighting more wisdom, greening and humanization.

Survey shows that students satisfied about the present situation of the school classroom lighting, and hope that the classroom light automatic control method is more intelligent and humanization. In addition, the blackboard glare phenomenon is serious, need to be further solved, Yao the [8], etc. Through the computer simulate the blackboard without glare lighting design.

\section{Objective to measure.}

1) Measuring equipment and instruments

Zhejiang university three color radiation spectrum analyzer SL - 300; Konica minolta luxmeter LS - 100; Laser range finder; Canon EOSM.

2) Measuring points

Direction of the classroom and the board size, installation of lamps and lanterns, quantity, type, color temperature, type, power, electrical parameters, such as the distance to the ground, ceiling lamps and lanterns, the classroom walls, ceiling, and the color and the material of the floor, the classroom and blackboard illumination.

3) Measuring method

The classroom and blackboard size measurement: according to GB/T17986.1-2000 [9], the 
trilateral measurement method is adopted.

Illumination measurement: according to GB/T 5700-5700 [10], the center location method is adopted.

Among them, in front of the classroom as the platform, is not a normal students face, so the corresponding area of illuminance will not be measured. Classroom illumination center location diagram is shown in figure 1.

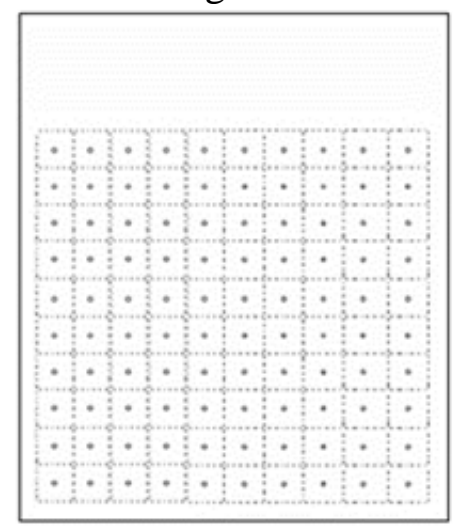

Fig.1 Center method of classroom

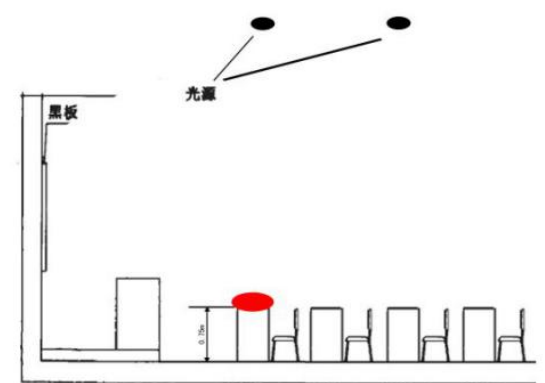

Fig.2 Center method of working-face

In view of student learning, working with a certain height, according to GB/T 3976-3976 [11], school classroom desks height is $0.75 \mathrm{~m}$. Students face illumination measurement diagram as shown in figure 2, the red areas for the working intensity of illumination measured height.

The blackboard illumination measurement center location diagram is shown in figure 3.

\begin{tabular}{|c|c|c|c|c|c|c|c|c|c|}
\hline 0 & 0 & 0 & 0 & 0 & 0 & 0 & 0 & 0 & 0 \\
\hline 0 & 0 & 0 & 0 & 0 & 0 & 0 & 0 & 0 & 0 \\
\hline 0 & 0 & 0 & 0 & 0 & 0 & 0 & 0 & 0 & 0 \\
\hline
\end{tabular}

Fig.3 Center method of blackboard

4) Data processing and analysis

a) The classroom and blackboard size measurement

Select A classroom as A representative of the small classroom, classroom size is: $8.18 \mathrm{~m} * 8.58$ $\mathrm{m} * 8.58 \mathrm{~m}$; Select the classroom B as a representative of the medium of the classroom, the classroom size is: $12.70 \mathrm{~m} * 9.20 \mathrm{~m} * 9.20 \mathrm{~m}$; District class $\mathrm{C}$ as a representative of the big classroom, classroom size is: $13.40 \mathrm{~m} * 13.40 \mathrm{~m} * 13.40 \mathrm{~m}$. Detailed dimension measurement data as shown in table 5.

By the calculation, different types of classroom chamber shape index respectively: the classroom A RI $=1.86$, the classroom B RI $=2.98$, the classroom $\mathrm{C} \mathrm{RI}=2.37$. Because of the actual chamber shape index and standard values, lighting power density threshold for correction, chamber shape index and revised as shown in table 4.

Tab.4 room index and LDP amendment value

\begin{tabular}{ccc}
\hline $\begin{array}{c}\text { Classroom } \\
\text { Name }\end{array}$ & room index & $\begin{array}{c}\text { Revised lighting power } \\
\text { density }\end{array}$ \\
\hline Classroom A & 2.98 & 8.28 \\
Classroom B & 1.86 & 9.00 \\
Classroom C & 2.37 & 8.28 \\
\hline
\end{tabular}

b) The classroom and blackboard illumination measurement

According to the classroom and the actual size of the blackboard, the center location method is adopted, using the LS - 100 luxmeter survey each classroom and blackboard illuminance value, and the data entry EXCEL spreadsheet. Classroom and blackboard is calculated using DIALux software and average intensity of illumination and the intensity of illumination evenness. The calculation results as shown in table 6 . 
Tab.5 The size measurement of classroom and blackboard

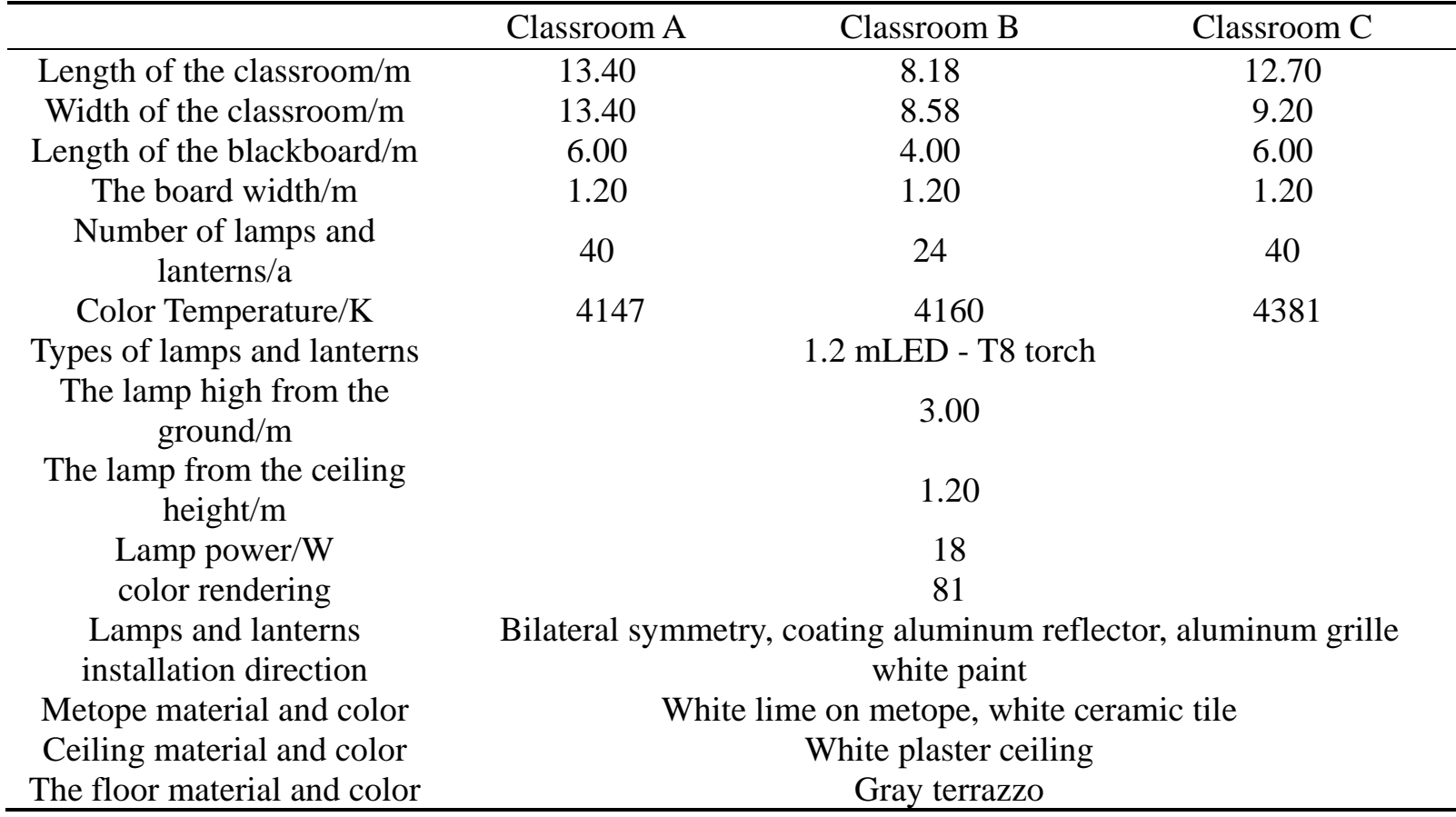

Tab.6 Average illumination and uniformity of illumination of classroom and blackboard

\begin{tabular}{ccccc}
\hline Classroom & $\begin{array}{c}\text { The average } \\
\text { intensity of } \\
\text { illumination/l } \\
\mathrm{x}\end{array}$ & $\begin{array}{c}\text { The classroom } \\
\text { illumination } \\
\text { evenness }\end{array}$ & $\begin{array}{c}\text { The } \\
\text { blackboard } \\
\text { average } \\
\text { illuminance/lx }\end{array}$ & $\begin{array}{c}\text { The blackboard } \\
\text { intensity of } \\
\text { illumination } \\
\text { evenness }\end{array}$ \\
\hline $\begin{array}{c}\text { Classroom } \\
\text { A }\end{array}$ & 348.25 & 0.85 & 166.90 & 0.84 \\
$\begin{array}{c}\text { Classroom } \\
\text { B }\end{array}$ & 364.18 & 0.74 & 185.63 & 0.92 \\
$\begin{array}{c}\text { Classroom } \\
\text { C }\end{array}$ & 338.37 & 0.78 & 168.73 & 0.85 \\
\hline
\end{tabular}

Tab.7 Standard evaluation of classroom illumination

\begin{tabular}{|c|c|c|c|c|}
\hline \multirow[b]{2}{*}{ lighting target } & \multicolumn{3}{|c|}{ Mearsurement } & \multirow[b]{2}{*}{ Standard numerical } \\
\hline & Classroom A & Classroom B & $\begin{array}{c}\text { Classroom } \\
\text { C }\end{array}$ & \\
\hline $\begin{array}{l}\text { Desktop illumination } \\
(\mathrm{lx})\end{array}$ & 348.25 & 364.18 & 338.37 & 300 \\
\hline $\begin{array}{l}\text { The blackboard } \\
\text { illumination (lx) }\end{array}$ & 166.90 & 185.63 & 168.73 & 500 \\
\hline $\begin{array}{c}\text { Desktop illumination } \\
\text { evenness }\end{array}$ & 0.85 & 0.74 & 0.78 & 0.60 \\
\hline $\begin{array}{c}\text { The blackboard lighting } \\
\text { uniformity }\end{array}$ & 0.84 & 0.92 & 0.85 & 0.70 \\
\hline $\begin{array}{l}\text { lighting power density } \\
(\mathrm{W} / \mathrm{m} 2)\end{array}$ & 4.01 & 6.16 & 6.16 & See table 4 \\
\hline room index & 2.98 & 1.86 & 2.37 & 1.5 \\
\hline color rendering（ $\mathrm{Ra} ）$ & 81 & 81 & 81 & $\geq 80$ \\
\hline light source & $\begin{array}{l}1.2 \text { mLED - } \\
\text { T8 torch }\end{array}$ & $\begin{array}{l}1.2 \mathrm{mLED}-\mathrm{T} 8 \\
\text { torch }\end{array}$ & $\begin{array}{l}1.2 \mathrm{mLED} \\
\text { - T8 torch }\end{array}$ & $\begin{array}{l}\text { Small diameter } \\
\text { straight tube } \\
\text { fluorescent lamp }\end{array}$ \\
\hline color temperature $(\mathrm{K})$ & 4147 & 4160 & 4381 & $\leq 4000$ \\
\hline $\begin{array}{l}\text { mounting height of } \\
\text { luminaire }(\mathrm{m})\end{array}$ & 3.00 & 3.00 & 3.00 & 3.00 \\
\hline
\end{tabular}


5) Outcome assessment

Through the school classroom lighting is subjective evaluation and objective data of measurement, high student satisfaction about the present situation of the school classroom lighting, automatic control mode of classroom and blackboard glare phenomena, remains to be further improved. Compared to the actual measurement results compared with the national standard, the results as shown in table 7 , the results showed that the classroom lighting illumination in the classroom, intensity of illumination uniformity, lighting power density, the light source color rendering, color temperature, lamps and lanterns installation height and blackboard illumination uniformity basically met the national standard, but serious deficiencies in the blackboard illumination.

\section{Recommendations for improvement}

For survey found insufficient blackboard intensity of illumination and glare and other problems, on the premise of guarantee does not produce glare, add the blackboard lamp, according to Liulin [12] on no glare effect of classroom lighting design optimization scheme and the building lighting design standard "regulation, the observer sitting eye height is $1.2 \mathrm{~m}$, standing eye height is $1.5 \mathrm{~m}$, and will not affect the normal teaching teachers, can be calculated, the blackboard lamp should be installed in the teachers' level of $45^{\circ}$ elevation above the line of sight, height $\mathrm{H}>2.45 \mathrm{~m}$, is apart from the blackboard $\mathrm{L}<0.53 \mathrm{~m}$. At the same time shows the CAD drawing of the classroom, as shown in figure 4.

To survey the lamps and lanterns of automatic control unreasonable problem, this paper recommend the use of multiple model control automatic lighting system [13], on the premise of energy conservation and environmental protection, in order to meet the needs of students in the classroom lighting. The classroom lighting can have the following four patterns: self-study mode, daytime mode, teaching mode, presentation mode.

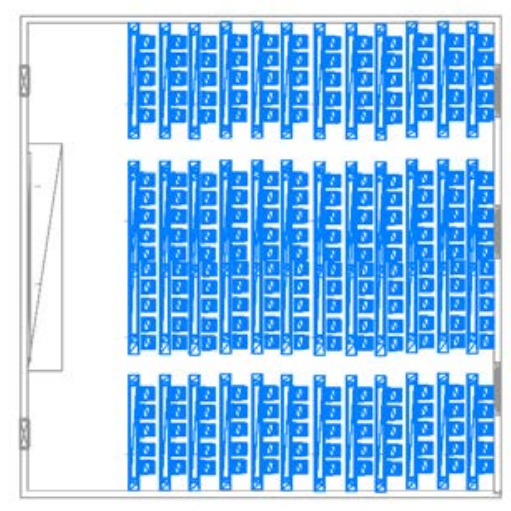

Fig.4 Classroom size

Self-study mode, when the evening self-study students, the classroom illumination constant lighting requirements, meet the requirement of "building lighting design standard", the science of classroom lighting, as shown in figure 5

Daytime mode, because of the uncertainty of the weather, the classroom illumination cannot be constant, and near the corridor side low intensity of illumination, in order to guarantee the classroom lighting to meet the new standards under the premise of reasonable fill light, to meet the needs of the students normal learning of illumination, as shown in figure 6 


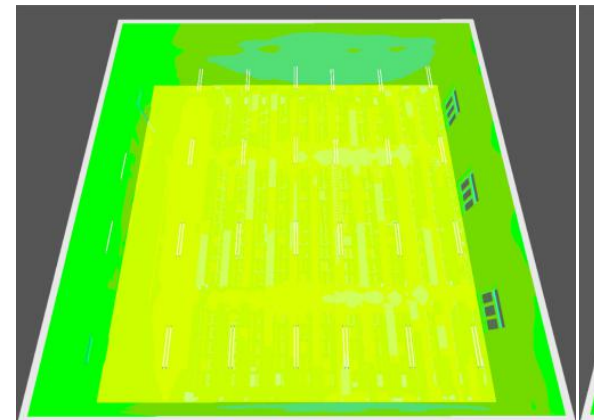

Fig. 5 Self-study mode

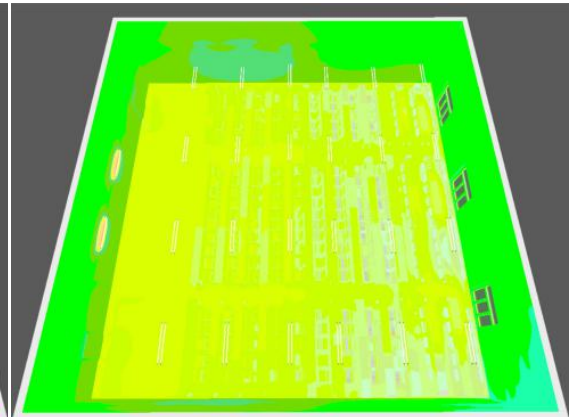

Fig.6 Day mode

Teaching mode, when teachers blackboard writing or tell the content, in the guarantee the blackboard does not produce glare with blackboard writing content under the premise of clear, open the blackboard lamp and the classroom lighting lamps and lanterns, and the real-time fill light as shown in figure 7 ;

Speech patterns, in the process of play and the speech, on the premise of guarantee the PPT content definition, the classroom in a reasonable manner to fill light, such as closing the blackboard lights, lamps and lanterns of open distance from the board, as shown in figure 8.

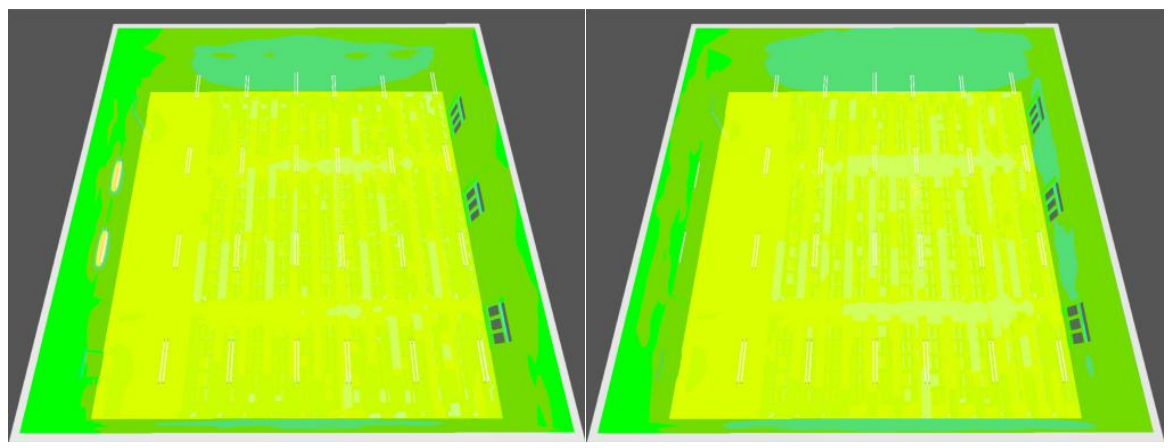

Fig.7 Teaching mode

Fig.8 Speech mode

To verify the improved classroom lighting effect, this article put DIALux software for simulating mode of classroom lighting lamps and lanterns of fully open, as shown in figure 9, in order to contrast before and after improvement of lighting effect. In addition to verify the classroom before and after modification evenness increased, at the same time using DIALux simulate the pseudo color image, respectively, as shown in figure 10 and figure 11.

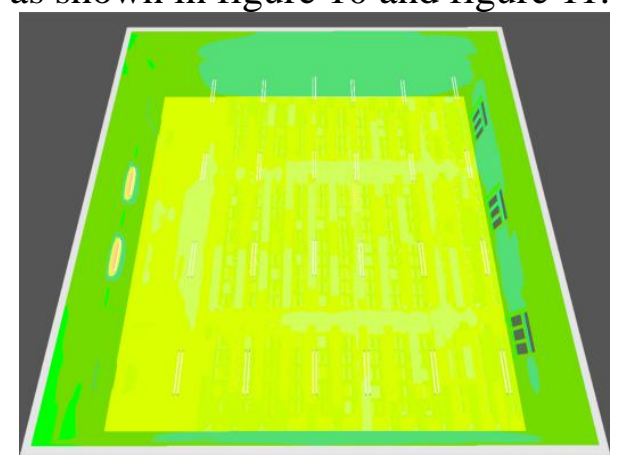

Fig.9 Fully open mode 


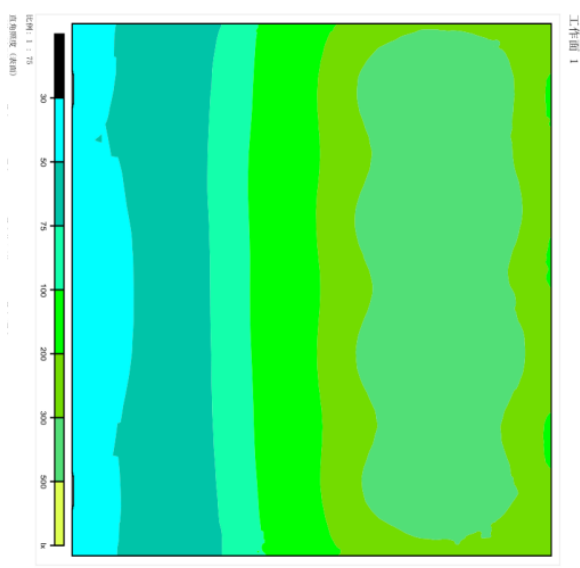

Fig.10 the actual state Pseudo Color

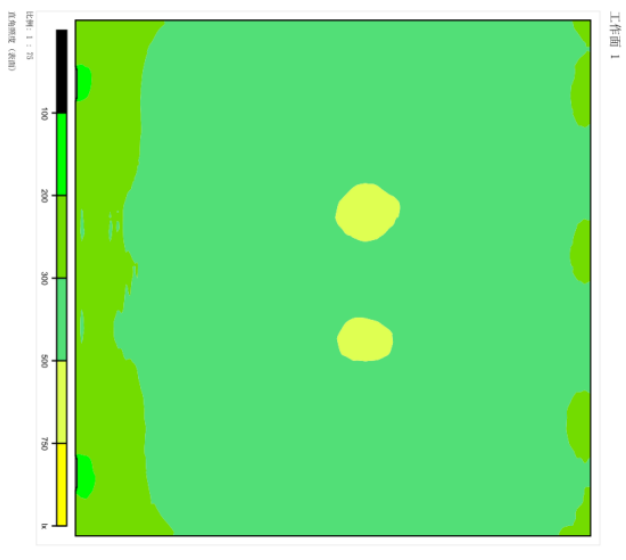

Fig.11 the imitate state Pseudo Color

\section{Conclusion}

The classroom as the main learning of students during the period of school location, the lighting environment myopia and the influence of physical and mental health is very important for students. To better build the classroom lighting environment, should with "building lighting design standard" and other national standards as the basis, aiming at health lighting [14], reasonable build appropriate classroom lighting light environment, to improve the students' vision, physical and mental health and learning efficiency is of great significance.

\section{Reference}

[1] People. National visual health report: 2020 Chinese in nearsightedness or exceeds 700million[EB/OL].(2015-06-09)[2015-07-15].

HTTP:http://scitech.people.com.cn/n/2015/0609/c1007-27123624.html.

[2] Zhang, cuckoo. Regular primary and secondary school classroom lighting design should pay attention to several problems [J]. Modern Chinese domain 12014 year 6.

[3] Hai-Jing Huang, Chen Gang. University of classroom lighting status and subjective evaluation of visual environment analysis [J]. Journal of lamps and lighting, 2010, 2010:22-26.

[4] Jin-Lan Han Lighting design Chun-Long Yang. Middle school. In August 2007, building electrical, electrical applications

[5] The People's Republic of China ministry of housing and urban and rural construction department. GB50034-2013 building lighting design standard [S]. Beijing: China building industry press.

[6] Li Tang Liu FengHua. University of ladder classroom lighting design and calculation [J]. Journal of taiyuan university of technology, 2008, 33:6, 119-122.

[7] Wen-Juan Hua, Ju-Xiang Jin, Xiao-Yan Wu,et al. Elevated light levels in schools have a protective effect on myopia[J].Ophthalmic and Physiological Optics, 2015, (03):252-262.

[8] Yaoqi Gu Peipei Zhao Haitian,. Classroom blackboard lamp lighting design and glare study [J]. China lighting appliances, 2013 01:1-4.

[9] The ministry of construction and the state bureau of surveying and mapping. GBT 17986.12000 property measuring 1 unit property measurement norms [S]. Beijing: China standard press, 2000.

[10] The national standardization technical committee. Ergonomics in GB/T 5700-2008 lighting method [S]. Beijing: China standard press, 2008.

[11] The health of the People's Republic of China. GB/T 3976-2002 school desks and chairs function dimension [S]. Beijing: China standard press, 2002. 
[12] Liulin, Dai Liling, Lu ZhangPing. Classroom lighting design optimization based on no glare effect [J]. Journal of lighting engineering, 2008, 12 (2) : 37-49.

[13] Yingming Gao, Huanyue Zhang, Nianyu Zou, et al. Daylight perceptive lighting and data fusion with artificial neutral network[J]. Optik - International Journal for Light and Electron Optics, 2014, (10): 2405-2408.

[14] Moon-Hwan Chang, Peter Sandborn, Michael Pecht, Winco K.C. Yung and Wenbin Wang.A return on investment analysis of applying health monitoring to LED lighting systems [J]. Microelectronics Reliability, 2015, (3/4):527-537.

Corresponding author: YU Ling:(1981-, Engineer, Email: yuling@dlpu.edu.cn) ;

First author: WANG Rong(1994-, postgraduate, Email: 474189984@qq. com) 